\title{
A estética da leitura em Julio Cortázar
}

Patrick Fernandes Rezende Ribeiro*

\section{Resumo:}

O presente artigo percorreu o romance Rayuela ( $O$ jogo da Amarelinha) de Julio Cortázar, que foi publicado pela primeira vez em 1963, elucidando e analisando a proposição de ato de leitura vinculada pela obra. Para isto, foram então vistas as noções de ato da leitura, os espaços em brancos e leitor implícito, derivados da teoria da estética da recepção de Hans Robert Jauss e Wolfgang Iser. Indo um pouco além, o estudo visou mostrar a que tipo de interpretação tais noções conduzem.

Palavras-chave: estética; leitura; leitor

\begin{abstract}
:
This article toured the novel Rayuela (Hopscotch) Julio Cortázar, which was first published in 1963, explaining and analyzing the reading act proposition bound by work. For this, then it was seen the act of reading notions of the spaces in white and implied reader, derived from the aesthetics of the theory of reception of Hans Robert Jauss and Wolfgang Iser . Going one-step further, the study aimed to show what kind of interpretation such notions lead.
\end{abstract}

Key-Words: esthetics; reading; reader

\section{Introdução}

Há alguns anos o que a crítica alemã chamou de "Rezeptionsästhetik" deu origem a teoria que tomou como objeto de estudo a relação entre texto e leitor, conhecida habitualmente como Estética da Recepção. Este estudo analisa a literatura como uma experiência estética, acreditando que o texto só pode ser interpretado a partir de sua recepção, isto é, a partir da análise da resposta do leitor ante os textos literários, e esta seria uma das questões a serem respondidas. O ponto de partida desta aproximação crítica à obra literária é, sem dúvida, a hermenêutica organizada a partir de H. G. Gadamer. É em sua obra A Verdade e o Método (1961) que a relação

\footnotetext{
* UNICAMP - Universidade de Campinas; Instituto de Estudos da Linguagem; Campinas; São Paulo; Brasil, patrick_ribeiro@ymail.com.
} 
entre texto e leitor passa a corresponder à lógica de pergunta e resposta. O texto é, antes, uma resposta a uma pergunta, em outras palavras, só apreendo num texto aquela coisa que traz algo que ver comigo. No entanto, o texto também traz perguntas, pois as repostas que ele me dá não me são inteiramente suficientes, e para respondê-las há o leitor ${ }^{1}$. Gadamer parte de Hegel e Heidegger para determinar que, para uma aproximação de uma obra literária do passado, o leitor traz consigo certos pré-conceitos ou preconceitos. Esses preconceitos do indivíduo são constitutivos de sua realidade histórica e vão tornar-se uma condição do entendimento da obra. Os princípios de Gadamer foram desenvolvidos e adaptados posteriormente pela crítica literária, e também, por vários de seus antigos alunos. Alguns de seus alunos na Universidade de Constança, formaram um grupo de teóricos, representado por Hans Robert Jauss e Wolfgang Iser, e na geração posterior, por Karlheinz Stierle, Rainer Warning, Wolf-Dieter Stempel e Hans Ulrich Gumbrecht. Na tradição angloamericana ao mesmo tempo, o Reader-Response Criticism, desenvolvem-se com autores como Gerald Prince, Stanley E.Fish, Jonathan Culler, David Bleich entre outros.

Hans Robert Jauss em seu estudo vai criticar diretamente a abordagem marxista e formalista porque, diferentemente destas, sua abordagem visa corrigir a concepção passiva do leitor na tríade formada pelo autor, obra e público. O público (leitor) é senão uma força histórica. "A vida histórica da obra literária é inconcebível sem o papel ativo que desempenha seu destinatário" (JAUSS, 1971, p. 68-69). Sua abordagem da recepção parte de dois tipos de horizontes: o "horizonte de expectativas" que está implicado diretamente na obra e o "horizonte de experiências" que é provido pelo receptor. Jauss restringe o campo de aplicação do método da estética da recepção defendendo que a essência da obra descansa em sua historicidade, ou seja, na sua relação com o leitor, numa dialética de horizontes de perguntas e respostas e para isto é necessário considerar que há uma distância estética entre eles (JAUSS, 2002).

Ao contrário de Jauss, que chega à estética da recepção a partir da história literária, Wolfgang Iser faz isso desde a New Cristicism e a Narratologia, e com

\footnotetext{
1 A lógica de pergunta e resposta se apresenta sob uma forma dialética, sob a forma do círculo hermenêutico. O que Gadamer posteriormente denominará de horizonte de perguntas.
} 
algumas influências da fenomenologia do R. Ingarden ${ }^{2}$. Enquanto o leitor de Jauss é um leitor empírico ou explícito, diferenciado social, histórica e biograficamente, Wolfgang Iser se concentra, indo mais além deste leitor, indo naquelas estruturas de consciência e propriedades textuais que envolvem o leitor no processo de leitura. Iser vê o leitor como pressuposto do texto e o texto como uma potencialidade. A obra é, então, um conjunto de sentidos constituídos pelo leitor ao longo da leitura. (ISER, 1972) Assim, a leitura só é concebida como constituição de sentido a partir do texto ou, por assim dizer, segundo as regras do jogo inscritas nele. Com isto, Iser centraliza seu estudo no texto individual e na relação que o leitor estabelece com este. Logo, o texto existe apenas na medida em que é lido, de modo que tanto o leitor e como o autor participam de um mesmo jogo imaginário. O leitor se move através do texto, é lançado à ação do texto ou da ausência deste que não são detalhados pelo autor: estes elementos têm um impacto sobre a imaginação do leitor, que cria seus próprios esboços como resultado da interação entre si e o texto. A leitura sempre é controlada pelo texto, para que quando um leitor interpreta um texto, a priori assuma atuar dentro dos limites estabelecidos no leitor implícito, pois “todo o texto é pré-orientado aos seus leitores potenciais" (ISER, 1972).

Por fim, a teoria da recepção aborda a obra através de duas perspectivas: a artística, que se refere ao texto criado pelo autor, e a estética, que é a concretização levada a cabo pelo leitor durante a leitura. É a convergência destas duas perspectivas que dotará a obra literária de existência.

Além destas duas abordagens sobre a recepção de uma obra temos a abordagem semiótica desenvolvida por Umberto Eco em Lector in fabula (1979); uma outra centrada no leitor real inaugurada por dois ensaios de Michel Picard: La lecture comme jeu (1986) e Lire le temps (1989); destacando a importância do leitor temos a visão sociológica de Levin Schücking. Wayne Booth acredita no leitor, em certa medida, como coautoria da obra, já que esta não se realizaria sem ele, como um tipo cumplicidade autor-leitor. Há ainda estudos que abordam a leitura performática entre outras.

Nossa pretensão aqui, não é de demonstrar como a obra Rayuela atende como

\footnotetext{
${ }^{2}$ A fenomenologia de Roman Ingarden considera toda obra de arte como um objeto intencional que é completado, estruturalmente, pelo leitor.
} 
exemplificação da concepção teórica da estética da recepção a partir de Jauss e Iser. Mas sim apresentar e comentar uma estética da recepção que se desgarra desta obra, e para isto, sim, recorremos a teoria citada.

\section{A leitura - entre um salto e outro se completam os espaços em branco.}

A crítica considera que Rayuela (1963) seria a obra pela qual Cortázar consegue reunir todos os elementos necessários para uma participação efetiva do leitor. A crítica lhe adjetiva como uma obra complicada, que exige boa memória e conhecimento de vários autores durante a leitura, que exige um esforço do leitor para o saltar das páginas e dos vais-e-vens inúmeros que o convidam a interagir com ela como copartícipe da busca existencial de seu protagonista e, que traz uma leitura que tem como resultado o sequestro do leitor, como objeto do jogo, dentro do romance perambulando tanto estrutural quanto subjetivamente. Esta foi uma das primeiras recepções da crítica do romance de Julio Cortázar.

A questão do leitor é um problema recorrente das aproximações críticas deste romance cortazariano e, consequentemente, também o ato da leitura. Problemática enfatizada e repercutida pelo próprio Cortázar em entrevistas, como por exemplo na entrevista dada a Ana María Hernández ${ }^{3}$ em que ele diz, respondendo a uma pergunta sobre seu romance Libro de Manuel (1968), "não saber e nem se interessar em saber quem morreu no romance e que isto está a cargo do leitor"; também pode-se verificar a importância que dava a este tema em seus textos críticos, como no ensaio sobre o romance ${ }^{4}$ em que defende a presença de alguns elementos retóricos no texto, pois estes possibilitariam ao leitor vir a ser copartícipe e compadecente da experiência pela qual passa o romancista: afirmação que está presente no texto de Rayuela na fala da personagem Morelli. Além de estar presente em seu romance de maior expressão (Rayuela) esta questão também se encontra presente em outros romances como o antes citado Libro de Manuel (1968), 62, Modelos para armar (1968) e Los cosmonautas de la cosmopista $(1984)^{5}$ e nos seus contos como é o caso do conto

\footnotetext{
3 “Conversación con Julio Cortázar”, septiembre de 1973. Esta entrevista está no Fundo Cortázar em uma versão datilografiada.

${ }^{4}$ CORTÁZAR, Julio. Valise de Cronópio. Tradução e Org. de Davi Arrigucci Jr. et al. São Paulo: Perspectiva, 1974.

${ }^{5}$ María Dolores Blanco Arnejo em seu livro La novela lúdica experimental de Julio Cortázar (1996) faz um estudo dos três romances citados, e posteriores a Rayuela, em sua análise destas obras defende que o romance lúdico se configura em especial nas evocações ao leitor.
} 
"Continuidad de los parques"6; neste, em particular, Cortázar parte do leitor como personagem e protagonista da narrativa, a que este lê uma narrativa que tem como final inusitado ele lendo que ele entrava pela porta com uma faca na mão e o encontrava lendo que ele entrava pela porta com uma faca na mão.

Não é incorreto dizer que Rayuela (o jogo da amarelinha), desde seu título, propõe uma relação participativa de caráter lúdico com o seu leitor. E que desde aí já está, propriamente, prescrito que o romance, na verdade, é um jogo. Jogo este que tem expostas as suas regras, ou melhor, suas instruções, no "Tablero de Direcciones". Neste tablero estabelece-se o tipo de leitura com a qual o leitor estará compactuando e necessariamente inclinado à atuar de imediato, ao menos com dois livros, ou seja, com duas leituras:

\begin{abstract}
A su manera este libro es muchos libros, pero sobre todo es dos libros. El primero se deja leer en la forma corriente, y termina en el capítulo 56, al pie del cual hay tres vistosas estrellitas que equivalen a la palabra Fin. Por consiguiente, el lector prescindirá sin remordimientos de lo que sigue.

El segundo se deja leer empezando por el capítulo 73 y siguiendo luego en el orden que se indica al pie de cada capítulo. En caso de confusión u olvido, bastará consultar la lista siguiente:

$73-1-2-116-(\ldots) 131-58$ - 131 Con el objeto de facilitar la rápida ubicación de los capítulos, la numeración se va repitiendo en lo alto de las páginas correspondientes a cada uno de ellos. (CORTÁZAR, 2005, p. 111)
\end{abstract}

A primeira proposta de leitura inicia-se no primeiro capítulo e vai seguindo adiante até encontrar-se no capítulo 56 em que deixa suspenso o restante do livro, pois ali estão as estrelinhas que equivalem a palavra "fim". A segunda proposta de leitura apresenta uma situação completamente diferente do que o leitor está acostumado, ele inicia sua leitura no capítulo 73 e segue a ordem que se indica ao rodapé de cada capítulo. Nesta leitura se descobrirá também que não se lerá todo o livro, e que a leitura terminará no capítulo 131. Engano do leitor, pois este capítulo lhe reserva uma brincadeira: ao final dele se indica para ir para o capítulo 58 que indica novamente para ir até o 131, e com isto o leitor fica aprisionado no universo fictício do texto perguntando-se qual capítulo corresponde ao fim. Novamente, a leitura exige uma nova tomada de ação, ou o leitor para no capítulo 131 e ponto, ou

\footnotetext{
${ }^{6}$ Presente no livro Final del Juego de 1974.
} 
escolhe outro caminho, o 58.

Contudo, quando Rayuela prescreve mais de uma forma de leitura ao leitor, ela também leva-o a tomar uma postura mais "ativa" antes mesmo de começar a narrativa. Pois ele, não só é persuadido a escolher uma das duas propostas de leitura do romance, como também é convidado a conceber a ideia de que é possível fazer outros caminhos de leitura por conta própria. O próprio romance faz acreditar que estes caminhos na verdade levariam ao leitor a repetir o caminho que o próprio autor realizou:

Posibilidad tercera: la de hacer del lector un cómplice, un camarada de camino. Simultaneizarlo puesto que la lectura abolirá el tiempo del lector y lo trasladará al del autor. Así el lector podría llegar a ser copartícipe y copadeciente de la experiencia por la que pasa el novelista (...) Lo que el autor de esa novela haya legrado para sí mismo, se repetirá (agigantándose, quizá, y eso sería maravilloso) en el lector cómplice... (453-454)

Levando ao fim, seriamente, uma das duas prescrições de leitura, o resultado encontrado desta organização foi a existência de uma série de "espaços em branco". Alguns exemplos destes espaços vazios podem ser observados na segunda proposta de leitura que leva ao leitor ao capítulo 48 e a rememoração nostálgica de Maga por Oliveira e em seguida o leva ao capítulo 111 e o leitor dá com o folhetim de Ivonne e Guitry, ou do capítulo 28 que narra a morte de Rocamadour e na sequência o direciona ao 130 onde narra os perigos do uso do zíper nas braguilhas das calças. Em todos estes saltos aparentemente desconectados existe uma tentativa de suprimir uma lógica narrativa, uma tentativa que visa dar a impressão de caos narrativo. No entanto, o que realmente há é uma narrativa que simula uma desordem através de uma descontinuidade e que convida, ou melhor, exige que seu leitor a organize e a reorganize continuamente. Considerando Rayuela como um texto que forma um sistema complexo de combinações, seu sistema abriga também um lugar para aquele que deve realizar as combinações. Esta complexa estrutura do texto, que faz parte do jogo proposto, traz dificuldades para a atuação em definitivo dessa proposição tortuosa por parte do leitor, que em alguns momentos é levado a um beco sem saída, devendo, nessa hora regressar para prosseguir. Estas dificuldades mostram, como veremos a seguir, que durante o ato da leitura o papel do leitor é necessariamente o de abdicar de uma situação cômoda para reconfigurar suas considerações sobre a 
narrativa, e só então conseguir prosseguir com um sentido unívoco. Prosseguir com a leitura corrigindo-a, ou melhor, reconfigurando-a, e mobilizando um horizonte de referências para cada nova situação proposta: o jogo então é um labirinto. Os lugares vazios condicionam a formação de representações do leitor, atividade agora empregada sob as condições colocadas pelo próprio texto. (ISER, 1999, p. 107). O lugar sistêmico é dado pelos lugares vazios, os quais são espaços vagos que assinalam enclaves no texto e exigem serem preenchidos pelo leitor, porém esta situação pode se desfazer à medida que o leitor é capaz de corrigir com suas próprias representações o romance sem necessariamente reconfigurar todos os saltos propostos ${ }^{7}$.

Uma das características intrínsecas do texto de Rayuela é a interrupção do discurso, existem inúmeras frases inacabadas. Como nos seguintes exemplos: passagem que narra a Maga contando o modo como foi violada em Montevidéu: “Tenía una manera de decir 'dário' que me hacía sentir como un hueco aquí...” (CORTÁZAR, 2005, p. 192); o final do capítulo 3 e 127: “Pez, hoja, nube, imagen: exactamente eso, a menos que...” (Idem, p. 144) e “A menos que.” (Idem, p. 678); passagem que fala sobre Horacio: "Es decir que las palabras, para Horacio..." (Idem, p. 206); passagem que narra Maga falando com o filho morto: "Parece increíble que alguna vez, Rocamadour. Ahora solamente aunque Horacio se ponga furioso y diga, pero a ti no te interesa" (Idem, p. 336); e para citar mais um exemplo, a passagem que narra o encontro de Horacio com Talita: "se pareciera un poco a esa otra mujer que" (Idem, p. 381).

Estas frases inacabadas são um mecanismo, que tem como finalidade incitar o leitor a concluí-las. Em último caso, elas estabelecem uma condição de interação entre texto e leitor. Fazem com que este atue dentro do texto, "ele é levado para dentro dos acontecimentos e estimulado a imaginar o não dito como o que é significado. Daí resulta um processo dinâmico, pois o dito parece ganhar sua significância só no momento em que remete ao que oculta" (ISER, 1999, p.106). Portanto, o processo de comunicação se põe em movimento e se regula não por causa de um código, mas mediante a dialética de mostrar e de ocultar. O leitor se depara com uma cadeia de espaços em branco que aparecem da leitura saltada do romance. Um dos motivos é a continua variação de temas entre os capítulos que faz com que a leitura saltada

\footnotetext{
${ }^{7}$ Neste ponto, o papel do leitor começa a tornar-se mais concreto. Pois agora ele terá de ocupar pontos de vista, de modo que o lugar do leitor, lugar ainda vazio e aquém do texto, deve ser até certo grau preenchido (ISER, 1996, p. 180)
} 
apresente muito mais espaços em branco. Com isto o que se pode concluir é que os espaços em branco são essenciais para estrutura de Rayuela, ou mais, são próprias da estrutura do romance, pois eles põem em movimento e até certo ponto regulam a interação entre texto e leitor.

Uma vez entendendo que só quando as representações do texto são relacionadas entre si e que o objeto imaginário ${ }^{8}$ só começa a se constituir pela operação que é realizada durante a leitura pelo leitor. Pode-se dizer que Rayuela é um livro de muitas leituras, ao contrário de dizer que é um livro de muitos livros, pois os lugares vazios e as frases inacabadas abrem uma multiplicidade de possibilidades, de maneira que as combinações dos esquemas textuais bem como o completar do discurso se tornam decisões optativas por parte do leitor. Porquanto "interrompendo a coerência do texto, os lugares vazios se transformam em estímulos para a formação de representações por parte do leitor" (ISER, 1999, p. 144).

Assim, a partir do momento em que Rayuela oferece como leitura o vai e vem descontinuado entre Paris, Buenos Aires e uma série de passagens aparentemente desconectadas: recortes de jornais, notas, poemas, etc, (técnica de collage). Pode-se considerar que Cortázar, numa tentativa de desautomatizar a leitura e reconfigurar o romance moderno, apresenta uma desordem narrativa, sob forma de uma nova ordem narrativa em Rayuela. Tal ordem aparece sempre como uma tendência desorganizadora, na medida em que transforma a uniformidade do romance em sequências que não se equivalem, mas, que ao mesmo tempo, não eliminam sua homogeneidade.

Já que uma obra literária "suscita lembranças de coisas já lidas, põe ao leitor em uma determinada atitude emocional e, desde o princípio, faz abrigar esperanças no que respeita ao "meio e fim" que no decorrer da leitura pode manter ou se desviar, mudar a orientação ou mesmo dissipar ironicamente, de acordo com certas regras do jogo do gênero ou a natureza do texto". (JAUSS, 1970, pp. 170-171).

Cortázar, em Rayuela, faz nascer na lembrança de seus leitores o Ulysses de Joyce$^{9}$, pois Rayuela tem como questão a viagem exterior e interior. E numa atitude paródica em relação a Homero, troca a peregrinação de Odisseu através do

\footnotetext{
${ }^{8}$ Entende-se aqui por imaginário aquilo que pode ser descrito literalmente (temas, motivos, intrigas, cenário), mas também que pode suscitar interpretações. (Wunenburger, 2007, p. 12)

${ }^{9}$ Comparação já feita por críticos da obra de Cortázar como: Andrés Amorós, Saúl Yurkievich, Jaime Alazraki, Davi Arrigucci, entre outros.
} 
Mediterrâneo pelas perambulações de Leopold Bloom em Dublín até chegar a Horacio Oliveira por Paris, ou no rememorizar de Buenos Aires, como já observaram alguns de seus críticos. Logo, Rayuela desperta de sua leitura um horizonte de expectativas que será familiar ao seu leitor ${ }^{10}$.

O que se infere da leitura feita do romance é que a proposta de leitura apresentada tem como fim levar o leitor ao "tempo do autor". Esta proposta, como foi dito anteriormente, também é sugerida na fala da personagem Morelli, talvez o representante mais fiel do autor implicado que é Cortázar, ${ }^{11}$ de Rayuela, na qual defende que: "la lectura abolirá el tiempo del lector y lo trasladará al tiempo del autor. Así el lector podría llegar a ser copartícipe o copadeciente de la experiencia por la que pasa el novelista, en el mismo momento y de la misma forma" (CORTÁZAR, 2005, p. 566) Esta proposta de leitura deixa ao leitor como responsável pela consolidação da obra, pois o que existe no texto nunca chegará a concretizar-se por completo a não ser pelo leitor, ou seja, aqui o texto manda fazer uma coisa e o contrário ler e ir para o tempo do autor.

Este estudo de Rayuela poderia, ainda, ter vislumbrado a questão da negação ${ }^{12}$, retomando uma categoria utilizada por Iser. No entanto, como foi exposto anteriormente, este estudo não visava de maneira nenhuma esgotar todas as possíveis abordagens da teoria da recepção no romance citado, nem, muito menos, fazer uma leitura de exemplificação desta teoria. Porém, tal questão pode ser vista no artigo de Santiago Juan- Navarro, sob o título "Un tal Morelli"13, onde se oferece um pequeno parágrafo sobre a "negação".

\section{O leitor implícito $\mathrm{x}$ leitor passivo}

Rayuela é um romance que apresenta dois caminhos narrativos um a história

\footnotetext{
${ }^{10}$ Reforçando: neste "o novo texto evoca para o leitor (ouvinte) o horizonte de expectativas que lhe é familiar de textos anteriores e as regras do jogo, que então são variados, corrigidos, modificados ou também só jogou. Variação e correção determinam a liberdade de movimento, modificação e reprodução dos limites da estrutura de um gênero" (JAUSS, 1970, p. 171).

${ }^{11} \mathrm{O}$ autor implicado é um conceito empregado por Wayne Booth, trata-se de um recurso retórico no qual uma imagem do autor real é criada pelo discurso. Em outras palavras, o autor real não desaparece propriamente, mas sim é representado, mascarado por uma voz narrativa que o recria na figura do narrador. (BOOTH, 1980, p. 167)

${ }^{12}$ Para Iser a negação produz um lugar vazio dinâmico no eixo paradigmático da leitura, ou seja, o que é familiar ao leitor é transgredido. A atenção deste será aumenta pelo fato de que as expectativas evocadas em virtude da presença do que é familiar são paralisadas pela negação. Assim, o leitor terá que tomar alguma atitude para solucionar esta ausência. Logo, é a negação que dará concretude ao lugar do leitor. (ISER, 1996, p. 171)

${ }^{13}$ Publicado na revista Canadiense de Estudios Hispánicos, Volumen XVI, 2, Invierno, 1992.
} 
de Oliveira e Maga e outro as reflexões de Morelli. Dentro de tais reflexões o leitor ocupa um lugar central, assim como a leitura da própria obra. O texto e a leitura dele se dão simultaneamente. Morelli, representante mais fiel do autor implicado, comenta sobre um romance, o próprio romance do qual é personagem, assim o romance se converte em objeto da teoria e também a prática dela em si mesmo. Assim o que este romance propõe é uma narrativa em que a participação do leitor é indispensável, pois ele também é um personagem da obra, como coloca a personagem Morelli: "hacer sentir que el verdadero y único personaje que me interesa es el lector" (CORTÁZAR, 2005, p. 608).

Representado pela personagem Morelli, o autor implicado divide o leitor em dois grupos os "lectores cómplices" e "lectores-hembras" (CORTÁZAR, 2005, p. $559)$.

O "lector cómplice" é aquele leitor ativo que assume uma cumplicidade com a obra, é copartícipe dela: "un cómplice, un camarada del camino" (CORTÁZAR, 2005 ,

p. 566). Pode-se dizer que o leitor cúmplice se assemelha ao leitor implícito de Iser: aquele que encarna todas as predisposições indispensáveis "para que a obra literária exerça seu efeito - predisposições providas, não por uma realidade empírica exterior, mas pelo próprio texto" (ISER, 1996, p. 36). "En general todo novelista espera de su lector que lo comprenda, participando de su propia experiencia, o que recoja un determinado mensaje y lo encarne.” (CORTÁZAR, 2005, p. 559).

Presente na estrutura da narrativa, o leitor implícito é uma construção do discurso, como uma personagem que idealiza ao leitor empírico pelo texto. A partir do conceito de leitor implícito proposto por Iser, o ato de leitura passa a ser percebido como a concretização do texto, ou seja, o leitor será aquele que responderá as perguntas do texto, através do ato da leitura preencherá os espaços em brancos, como já comentamos anteriormente. O leitor implícito sem necessariamente defini-lo: “préestrutura o papel a ser assumido pelo receptor, e isso permanece verdadeiro mesmo quando os textos parecem ignorar seu receptor potencial ou excluí-lo como elemento ativo. Assim, o conceito de leitor implícito designa uma rede de estruturas que pedem uma resposta, que obrigam o leitor a captar o texto" (ISER, 1996, p. 36). 
O "lector-hembra" é aquele leitor passivo que gosta de leituras simples e dadas totalmente pelo texto e seu autor, como se pode observar no seguinte fragmento do romance:

Un tipo que no quiere problemas sino soluciones, o falsos problemas ajenos que le permiten sufrir cómodamente en su sillón, sin comprometerse en el drama que también debería ser el suyo. (CORTÁZAR, 2005, p. 601)

Toda a estrutura de Rayuela, desde o "tablero de dirección", está fundamentada na cumplicidade desse leitor ativo. Segundo Morelli o romance tem como objetivo: "Intentar en cambio un texto que no agarre al lector pero que lo vuelva obligadamente cómplice al murmurarle, por debajo del desarrollo convencional, otros rumbos más esotéricos" (CORTÁZAR, 2005, p. 559), pois para ele só assim, ambos, leitor e autor atuam juntos: “¿Para qué sirve un escritor sino para destruir la literatura? Y nosotros, que no queremos ser lectores-hembra, ¿para qué servimos sino para ayudar en lo posible a esa destrucción?”. (CORTÁZAR, 2005, p. 614).

Assim, a disposição do romance e a voz do autor implicado levam a acreditar que a leitura cronológica proposta no "tablero de dirección" está destinada ao "lector- hembra", enquanto que a leitura saltada, a segunda proposta, por causa de sua complexidade pressupõe seu destino ao "lector cómplice". Afirmar tal conjectura seria um equívoco deste estudo, pois a obra é feita para um único tipo de leitor, o que a lê, e este é sempre um leitor cúmplice dela, pois senão ela nunca se realizaria. O "lector- hembra", ingênuo, passivo, independente da proposta de leitura que opte, fará a sua leitura e atuará nela, bem como o "lector cómplice", implicado, implícito, leal, ideal, fará a sua das duas propostas. Talvez, o "lectorhembra" possa aproveitar mais a dimensão lúdica do texto, enquanto que o "lector cómplice", pode utilizar seu repertório para reconfigurar o texto ou perder-se tentando.

No entanto, o leitor que Rayuela evoca nunca será um leitor passivo (lectorhembra), pois o seu autor Cortázar impede que o seja ao obrigá-lo sempre a escolher, desde a primeira página, a maneira que lerá o romance. O romance está dividido em três partes com 155 capítulos. A primeira parte, "Del lado de allá", vai do capítulo 1 ao 36. A segunda, "Del lado de acá", vai do capítulo 37 ao 56. A terceira e última "De otros lados (capítulos prescindibles)", vai do capítulo 57 ao 155. O início é o "Tablero de dirección", nele o autor instrui o leitor sobre como ler o libro, dando-lhe duas opções, e o leitor: "queda invitado a elegir una de las 
dos posibilidades" (CORTÁZAR, 2005, p. 111). Induzido pelo carácter "retórico persuasivo" do "Tablero de dirección", uma série de perguntas é criada pela expressão "remordimientos" localizada antes da introdução da segunda proposta de leitura: "el lector prescindirá sin remordimientos de lo que sigue." (CORTÁZAR, 2005, p. 111), pois a partir dela o leitor perceberá que ao escolher uma das opções ficará sem ler grande parte do livro, logo, sua escolha acaba sendo dolorosa. Pode-se dizer que o objetivo final da obra é deixar à responsabilidade do leitor a sua conclusão ou não, pois as diferentes leituras do texto serão configuradas por ele, como uma criação imaginária, que está sendo constantemente revisada durante o ato da leitura, pois: "lo que busca Morelli es quebrar los hábitos mentales del lector" (CORTÁZAR, 2005, p. 615).

\section{Conclusão}

Este trabalho teve como objetivo abordar o ato da leitura e o leitor no romance Rayuela de Julio Cortázar. Para isto, foram então vistas as noções de ato da leitura, os espaços em brancos e leitor implícito, derivados da teoria da estética da recepção de Hans Robert Jauss e Wolfgang Iser. E desta abordagem se concluiu que de fato uma obra não se destina somente a um leitor, que algumas leituras sofrem limitações específicas, que o texto literário também cria seus leitores, e que tudo isto se dá pelo jogo discursivo e pela dinâmica estrutural do texto.

Se o objetivo fosse exemplificar a teoria, concordaríamos que: o "tablero de dirección”, os espaços em branco, os saltos de capítulos e as ponderações da personagem Morelli sobre o leitor do romance ("lector cómplice" e "lector hembra"), mostram que a leitura proposta pelo romance é uma leitura de sabatina das habilidades de antevisão e compreensão do leitor.

O que se torna evidente é que a leitura não é dominável, pois uma vez considerado o leitor participativo na construção de sentido de um texto cria-se uma distância considerável da ideia de uma leitura definitiva. Já que tal aproximação tende a um subjetivismo, pois se suspeita que, na tentativa de apontar os percursos de leitura hipoteticamente existentes e os sugeridos no "tablero de dirección" do romance utilizado, o que talvez tenha prevalecido foi uma leitura pessoal do romance. Aproveitase para reiterar que o fato de que a aproximação crítica aplicada aqui não pode ser 
mais que uma interpretação dentro de um momento de análise de uma obra. Esta recepção pode ser traduzida poeticamente assim: "leyendo el libro, se tenía por momentos la impresión de (...) que la acumulación de fragmentos cristalizara bruscamente en la realidad total" (CORTÁZAR, 2005, p. 647).

Como discutido no decorrer do estudo, reitera-se aqui o fato de que a perspectiva teórica aplicada não pode ser mais que um instrumento dentro de um momento de análise de uma obra. A utilização de uma ou outra teoria não diminui a importância de uma obra literária ${ }^{14}$. E que fatalmente ao aplicar um modelo teórico ao texto, o que se tem é uma interpretação já pré-moldada por este modelo.

\section{Referências}

CORTÁZAR, Julio. Rayuela. Madrid: Ediciones Cátedra, 2005.

BOOTH, Wayne. A retórica da ficção. Tradução Maria Teresa H. Guerreiro. Lisboa: Arcádia, 1980.

CULLER. Jonathan. Teoria literária: uma introdução. São Paulo: Beca. 1999.

DURÃO, Fabio Akcelrud. Teoria (literária) americana: uma introdução crítica. Campinas: Autores Associados, 2011. - (Coleção Ensaios e Letras).

EIKHENBAUM, B. "La Théorie de la 'Méthode Fornelle"”. In: V. A., Théorie de la Littérature, 1966.

IGARDEN, Roman. A obra de arte literária. Trad. Albin E. Beau, Maria da Conceição Puga e João F. Barrento. $3^{\mathrm{a}}$ ed. Lisboa: Fundação Calouste, Gulbenkian,1965

ISER, Wolfgang. $O$ ato da leitura - uma teoria do efeito estético. Tradução de Johannes Kretschmer. São Paulo: Editora 34,1996. V.1

- O ato da leitura - uma teoria do efeito estético. Tradução de

Johannes Kretschmer. São Paulo: Editora 34,1996. V.2

. "E proceso de lectura: enfoque fenomenológico". In.: Estética de la recepción. Compilación de José Antonio Mayoral. Madrid: Arco/ Libros, 1987.

. A indeterminação e a resposta do leitor na prosa de ficção. Cadernos do Centro de Pesquisa Literárias da PUCRS, Porto Alegre: PUC-RSv. 3, n.2, março 1999.

O ato da leitura: uma teoria do efeito estético. Trad. de Johannes Kretschmer.

São Paulo: Editora 34, 1999a. v. 2.

Teoria da recepção: uma reação a uma circunstância histórica. In: ROCHA, J. C. de C. (Org.). Teoria da Ficção: indagações à obra de Wolfgang Iser. Trad. de Bluma W. Vilar e João C. de C. Rocha. Rio de Janeiro: EdUERJ. 1999b2.p. 19-34.

O fictício e o imaginário. In: ROCHA, J. C. de C. (Org.). Teoria da Ficção: indagações à obra de Wolfgang Iser. Trad. de Bluma W. Vilar e João C. de C. Rocha. Rio de Janeiro: EdUERJ. 1999c. p. 63-78.

O jogo. In: ROCHA, J. C. de C. (Org.). Teoria da Ficção: indagações à obra de Wolfgang Iser. Trad. de Bluma W. Vilar e João C. de C. Rocha. Rio de Janeiro: EdUERJ. 1999.

\footnotetext{
${ }^{14}$ A conclusão deste trabalho é consonante com a seguinte afirmação de Durão: “O paradoxo da interpretação é que se, por um lado, o domínio de um amplo repertório teórico abre infinitamente o horizonte possível do sentido; por outro, para que faça jus ao objeto - ou, de novo, para que ele possa simplesmente surgir como tal, e não como exemplo do conceito -, é necessário que ele seja abordado com uma ingenuidade autoconsciente". (DURÃO, 2011, pp. 119 - 120)
} 
JAUSS, Hans Robert. Historia de la literatura como provocación de la teoría literaria. 1970.

- Pequeña apología de la experiencia estética. Barcelona -Buenos Aires México: Ediciones Paidós, 2002.

. "El lector como instancia de una nueva historia de la

literatura". In.: Estética de la recepción. Compilación de José Antonio Mayoral. Madrid: Arco/ Libros, 1987.

JOUVE, Vicent. A Leitura. Tradução Brigitte Hervor. São Paulo: Editora UNESP, 2002. LIMA, Luiz Costa (organização e tradução). A literatura e o leitor. Texto de estética da recepção. $2^{a}$ ed. Ver. Ampl. São Paulo: Paz e Terra, 2002.

TODOROV, T. Teoria da Literatura I: Textos dos Formalistas Russos. Lisboa: Edições 70, 1999.

WUNENBURGER, Jean-Jacques. O imaginário. Tradução de Maria Stela Gonçalves. São Paulo: Edições Loyola, 2007.

YUNES, E. Tecendo um leitor: uma rede de fios cruzados. Curitiba: Aymará, 2009.

ZILBERMAN, Regina. Estética da recepção e História da literatura. São Paulo - Ática, 1989. 